\title{
MEMBANGUN WEBSITE MALL MESRA INDAH DENGAN MENGGUNAKAN METODE UCD (USER CENTER DESIGN)
}

\author{
Shinta Palupi ${ }^{1)}$, Siti Lailiyah ${ }^{2)}$, Shendy Indra Wijaya ${ }^{3)}$ \\ ${ }^{1}$ Sistem Informasi, STMIK Widya Cipta Dharma \\ ${ }^{2,3}$ Teknik Informatika, STMIK Widya Cipta Dharma \\ $1,2,3$ Jl. Prof. M. Yamin No. 25, Samarinda, 75123 \\ E-mail : caca_200177@gmail.com ${ }^{1)}$, lail.59a@gmail.com ${ }^{2}$, centdy@gmail.com ${ }^{3)}$
}

\begin{abstract}
ABSTRAK
Mall Mesra Indah Samarinda adalah merupakan pusat perbelanjaan yang bergerak dalam bidang penjualan khususnya Mal Pertama yang hadir di Samarinda Provinsi Kalimantan Timur. Sampai saat ini pengenalan toko-toko dan promosi masih sebatas iklan melalui baliho dan spanduk.

Metode yang digunakan pada penelitian ini meliputi metode pengumpulan data yaitu penelitian lapangan dan penelitian kepustakaan, sedangkan metode pengembangan sistem yang digunakan dalam pengembangan website ini adalah metode User Centered Design (UCD) yang terdiri dari fokus pada pengguna, perancangan terintegrasi, dari awal berlanjut pada, Pengujian pengguna, perancangan interaktif. Dengan bantuan tools seperti unified modeling language(UML), use case diagram, activity diagram, state chart diagram, sequence diagram, dan class diagram.

Penelitian ini dilakukan bertujuan untuk membuat Website Mall Mesra Indah Samarinda yang memudahkan para pengunjung Mall Mesra Indah dalam mencari info barang atau produk terbaru yang di jual Serta Informasi lengkap mengenai Mall Mesra Indah. Metode yang digunakan dalam pengembangan sistem menggunakan metode User Center Design(UCD). Alat bantu pengembangan sistem yang digunakan yaitu Unified Modeling Languange (UML) dengan menggunakan bahasa pemrograman Php, Javascript dan XML serta database MySQL.
\end{abstract}

Kata Kunci: Website, Mall, Mesra Indah, Pusat Perbelanjaan,Online, Belanja, UCD

\section{PENDAHULUAN}

Web merupakan salah satu sumber informasi yang banyak dipakai. Sebagai suatu aplikasi, web dibuat dengan tujuan agar pemakai dapat berinteraksi dengan penyedia informasi dengan mudah dan cepat, yaitu melalui dunia internet. Aplikasi web tidak lagi terbatas sebagai pemberi informasi informasi statis, melainkan juga mampu memberikan informasi dinamis, dengan melakukan koneksi database. Dengan target itu maka banyak dibuat slogan-slogan, banner-banner, buildboardbuildboard sampai dengan web company profile yang bermanfaat untuk mempromosikan suatu perusahaan sehingga suatu perusahaan dapat dikenal oleh masyarakat luas. Dalam hal ini web salah satu media informasi yang mudah dan luas jangkauannya, supaya para konsumen dapat mengetahui tentang Mall Mesra Indah baik dalam negeri maupun luar negeri.

Melihat kebutuhan itu maka Mall Mesra Indah memerlukan website untuk memberikan info tentang profil pusat perbelanjaan sehingga masyarakat luas termasuk turis asing mengetahui informasi tentang profil pusat perbelanjaan tersebut. Mall Mesra Indah dapat di kenal di masyarakat luas. Dengan web ini semua informasi tentang profil pusat perbelanjaan Mall Mesra Indah dapat disajikan dengan mudah, cepat dan up to date. Berdasarkan uraian di atas maka kami akan membuat sebuah website company profile tentang
Mall Mesra Indah agar Mall Mesra Indah lebih dikenal di masyarakat luas dan dapat berkembang dengan baik sesuai dengan perkembangan zaman. Berdasarkan permasalahan diatas maka perlu dibangun sebuah usulan Membangun Website Mall Mesra Indah menggunakan teknologi javascript dan silverlight dengan metode UCD (User Center Design)dengan harapan agar dapat memudahkan konsumen dalam melakukan pengenalan dan promosi yang ada di website Mall Mesra Indah Samarinda yang terhubung dengan internet.

\section{RUANG LINGKUP PENELITIAN}

1. Rumusan Masalah

Berkaitan dengan Latar Belakang yang telah di uraikan di atas, maka ada beberapa hal yang perlu di rumuskan dalam masalah ini yaitu : "Bagaimana Membangun website Mall Mesra Indah dengan menggunakan metode UCD (User Center Design)".

2. Batasan Masalah

Adapun Batasan masalah dari sistem ini adalah untuk menghindari analisis yang berkepanjangan dan mengingat luasnya ruang lingkup permasalahan yang ada, Batasan masalah di sini adalah:

1. Halaman Front End

1. Melihat Menu Utama

2. Melihat Company Profile

3. Melihat Isi Daftar Toko/Counter 
4. Melihat Berita dan Event

5. Melihat Gallery

6. Melihat Halaman Banner

7. Melakukan Pemesanan Sewa Petak Pameran

8. Menyediakan Fasilitas Belanja Online

2. Halaman Back End

1. Pemeliharaan Login Dan Password Untuk Admin

2. Pemeliharaan Isi Data Profile

3. Pemeliharaan Data Event Dan Berita

4. Pemeliharaan Data Gallery

5. Melakukan Update Produk

6. Melihat History Transaksi

7. Pemeliharaan Data Banner

8. Pemeliharaan Testimonial

\section{BAHAN DAN METODE}

\subsection{Penjelasan Dan Bahan}

menurut Burhan R.M (2003), Internet berasal dari kata Interconnection Networking yang mempunyai hubungan komputer dengan berbagai tipe yang membentuk jaringan yang mencakup seluruh dunia (jaringan komputer global) dengan melalui jalur telekomunikasi seperti telepon, radio link, satelit dan lainnya. Setiap komputer dan jaringan terhubung secara langsung maupun tidak langsung ke beberapa jalur utama yang disebut "internet backbone" dan dibedakan satu dengan yang lainnya menggunakan "unique name" yang biasa disebut dengan alamat "IP" 32 bit, contoh : 202.15932.0 (indo.net.id). Dengan Internet kita dapat melakukan semua aktivitas informasi seperti menonton, baca berita,belanja maupun download bahan apa saja yang ada di internet.

Menurut Jhonsen (2004), Internet merupakan kumpulan dari halaman-halaman web yang berhubungan dengan file-file lain yang saling terkait. Adapun layanan informasi tersebut dapat disisipi dengan berbagai hal yang ditawarkan oleh pengelola website guna diperoleh suatu manfaat website dilengkapi sebuah support sistem yang berguna sebagai sarana interaksi dengan pengunjung website tersebut.

Internet bagaikan sebuah pusat informasi terbesar di dunia dan website adalah sebagai salah satu informasi istilah-istilah di pusat informasi tersebut. Dengan website seseorang tidak harus meninggalkan aktivitasnya seperti bekerja, sekolah, dll. Hal diatas dapat dilakukan dengan mengakses salah satu website yang telah memberikan layanan informasi yang diinginkan secara langsung melalui internet.

Javascript diambil dari dua suku kata yaitu java dan script java adalah bahasa pemograman yang berorientasi object. Script adalah serangkaian intruksi program secara fungsinya, JavaScript digunakan untuk menyediakan akses script pada objek yang dibenamkan (embedded). Contoh sederhana dari penggunaan JavaScript adalah membuka halaman pop up, fungsi validasi pada form sebelum data dikirimkan ke server, merubah image kursor ketika melewati objek tertentu, dan lain lain.
World Wide Web menurut Sutarman (2009), sering disingkat WWW atau "web" saja, yakni sebuah sistem dimana informasi dalam bentuk teks, gambar, suara, dan lain-lain dipresentasikan dalam bentuk hypertext dan dapat diakses oleh perangkat lunak yang disebut browser. Informasi di web pada umumnya ditulis dalam format HTML. Informasi lainnya disajikan dalam bentuk grafis (dalam format GIF, JPG, PNG), suara (dalam format $\mathrm{AU}, \mathrm{WAV}$ ), dan objek multimedia lainnya (seperti MIDI, Shockwave, Quicktime Movie, 3D World). WWW dijalankan dalam server yang disebut HTTPD. Sedangkan menurut Burhan (2003), World Wide Web adalah kumpulan homepage di internet.

\subsection{Metode User Center Design (UCD)}

UCD ( User Centered Design ) merupakan paradigma baru dalam pengembangan sistem berbasis web. Perancangan berbasis pengguna (User Centered design = User Centered Design = UCD) adalah istilah yang yang digunakan untuk untuk menggambarkan filosofi perancangan. Konsep dari UCD adalah user sebagai pusat dari proses pengembangan sistem, dan tujuan/sifatsifat, konteks dan lingkungan sistem semua didasarkan dari pengalaman pengguna. Prinsip yang harus diperhatikan dalam UCD adalah:

\section{Fokus pada pengguna}

Perancangn harus berhubungan langsung dengan pengguna sesungguhnya atau calon pengguna melalui interview, Survey, dan partisipasi dalam workshop perancangan.

Tujuannya adalah untuk memahami kognisi, karakter, dan sikap pengguna serta karakteristik anthropometric. Aktivitas utamanya mencakup pengambilan data, analisis dan integrasinya ke dalam informasi perancangan dari pengguna tentang karakteristik tugas, lingkungan teknis, dan organisasi.

\section{Perancangan terintergrasi}

Perancangan harus mencakup antarmuka pengguna, sistem bantuan, dukungan teknis serta prosedur instalasi dan konfigurasi.

3. Dari awal berlanjut pada penggujian pengguna

Satu-satunya pendekatan yang sukses dalam perancangan sistem yang berpusat pada pengguna adalah secara empiris dibutuhkan observasi tentang kelakuan pengguna, evaluasi umpan-balik yang cermat, wawasan pemecahan terhadap masalah yang ada, dan motivasi yang kuat untuk mengubah rancangan.

\section{Perancangan interaktif.}

Sistem yang sedang dikembangkan harus didefinisikan, dirancang, dan ditest berulang kali. Berdasarkan hasil test kelakuan dari fungsi, antarmuka, sistem bantuan, dokumementasi pengguna, dan pendekatan pelatihannya. 
ISO 13407:1999 Human-centered design process for interacti

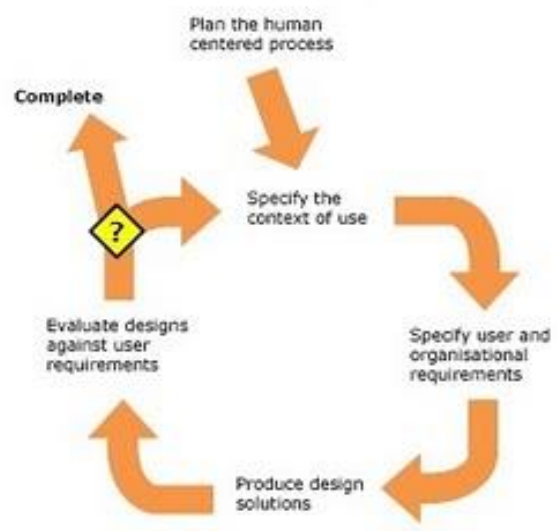

Gambar 1. Gambar Proses UCD berdasarkan ISO 13407:1999

Keterangan gambar:

1. Memahami dan menentukan konteks pengguna

2. Menentukan kebutuhan pengguna dan Organisasi

3. Solusi perancangan yang dihasilkan

4. Evaluasi Perancangan terhadap kebutuhan pengguna

\section{RANCANGAN SISTEM/APLIKASI}

\subsection{Usecase Diagram}

Menggambarkan aktivitas yang dapat dilakukan oleh sistem dari sudut pandang user sebagai pemakai (external observer) dan berhubungan dengan skenario-skenario yang dapat dilakukan oleh user.

Gambar disain Website Mall Mesra Indah dari 9 Usecase yang diwakili dengan gambar elips, dan 2 buah actor pengguna.

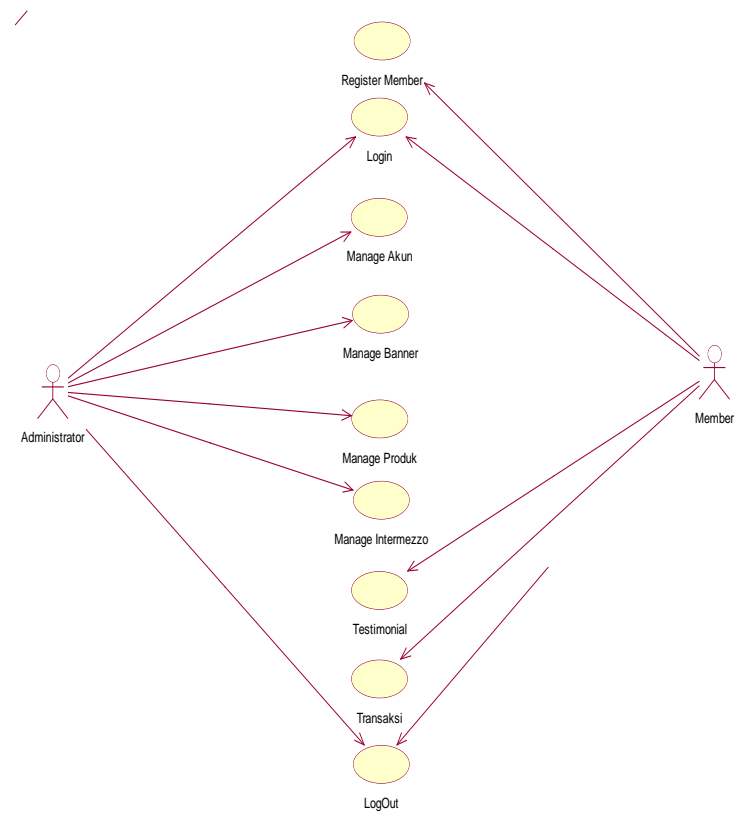

Gambar 2. Gambar Proses Usecase diagram Mall Mesra Indah
Tabel 4.1 Keterangan Diagram Usecase Website

Mal Mesra Indah

\begin{tabular}{|c|c|}
\hline $\begin{array}{l}\text { Nama Use } \\
\text { Case }\end{array}$ & Use Case Website Mal Mesra Indah \\
\hline $\begin{array}{l}\text { Deskripsi } \\
\text { Singkat }\end{array}$ & $\begin{array}{l}\text { Administratormanagedata } \\
\text { pengguna. }\end{array}$ \\
\hline Aktor & Administrator\& Member \\
\hline $\begin{array}{l}\text { Tindakan } \\
\text { Utama }\end{array}$ & $\begin{array}{l}\text { 1. Mengelola data pengguna } \\
\text { 2. Memiliki akses untuk } \\
\text { memanage } \\
\text { akun,banner,produk,interm } \\
\text { ezzo dah history transaksi }\end{array}$ \\
\hline
\end{tabular}

adapun perincian usecase adalah sebagai berikut :

\section{Usecase :}

1) Login : halaman login untuk masuk kedalam system administrator website.

2) Menu dashboard : tombol untuk menuju ke halaman admin untuk melakukan manajemen akun.

3) Menu Banner : tombol untuk menuju kehalaman admin melakukan pengaturan banner iklan yang ada dihalaman website.

4) Menu Produk: tombol untuk menuju ke halaman admin untuk melakukan editing produk dimana pengguna dapat mengelola data produk baik menambah kategori ataupun menambah produk.

5) Menu Member \& Testimonial: tombol untuk menuju ke halaman admin melakukan pengaturan member aktif dan yang mengirimkan testimonial apakah akan ditampilkan atau tidak pesannya.

6) Menu Intermezzo:tombol untuk menuju ke halaman admin untuk melakukan editing artikel atau memasukan berita.

7) Menu Register Member: tombol untuk menuju ke halaman member untuk mendaftar jadi member agar bisa melakukan pembelanjaan secara online di situs ini.

8) Menu Transaksi : tombol untuk menuju ke halaman admin untuk melihat history transaksi yang telah dilakukanoleh para member.

9) Logout : Tombol untuk keluar dari system administrator website.

\subsection{Struktur database}

1. Tabel Data Admin

Nama Tabel : tbl_spr_admin

Primary Key : kode_spr_admin 
Tabel 4.1 Data Admin

\begin{tabular}{|c|c|c|c|}
\hline Field & Type & Panjang & Keterangan \\
\hline Kode_spr_admn & Int & 10 & Kode admin \\
\hline Username_admn & Varchar & 50 & $\begin{array}{c}\text { Username } \\
\text { admin }\end{array}$ \\
\hline Pass_admn & Varchar & 100 & $\begin{array}{c}\text { Password } \\
\text { admin }\end{array}$ \\
\hline Nama_admn & Varchar & 100 & Nama admin \\
\hline Stts & Varchar & 20 & Status \\
\hline Lvl & Varchar & 20 & Level \\
\hline Email & Varchar & 50 & Email admin \\
\hline Alamat & Text & & Alamat admin \\
\hline Tgl_lahir & Varchar & 50 & $\begin{array}{c}\text { Tanggal Lahir } \\
\text { admin }\end{array}$ \\
\hline
\end{tabular}

2. Tabel Data User

Nama Tabel : tbl_user

Primary Key : kode_user

Tabel 4.2 Data User

\begin{tabular}{|c|c|c|c|}
\hline Field & Type & Panjang & Keterangan \\
\hline Kode_user & Int & 10 & Kode user \\
\hline Username_user & Varchar & 100 & $\begin{array}{c}\text { Username } \\
\text { user }\end{array}$ \\
\hline Pass_user & Varchar & 200 & $\begin{array}{c}\text { Password } \\
\text { user }\end{array}$ \\
\hline Nama & Varchar & 200 & Nama user \\
\hline Email & Varchar & 200 & Email user \\
\hline Alamat & Text & Alamat user \\
\hline Telpon & Varchar & 50 & Telpon user \\
\hline Propinsi & Varchar & 200 & $\begin{array}{c}\text { Propinsi } \\
\text { user }\end{array}$ \\
\hline Kota & Varchar & 200 & Kota user \\
\hline Kode_Pos & Varchar & 30 & $\begin{array}{c}\text { Kode pos } \\
\text { user }\end{array}$ \\
\hline Tgl_Lahir & Varchar & 50 & $\begin{array}{c}\text { Tanggal } \\
\text { Lahir }\end{array}$ \\
\hline Stts & Int & 1 & Status user \\
\hline Kode_aktivasi & Varchar & 200 & $\begin{array}{c}\text { Kode } \\
\text { aktivasi user }\end{array}$ \\
\hline Tgl_transaksi & Varchar & 30 & $\begin{array}{c}\text { Tanggal } \\
\text { transaksi }\end{array}$ \\
\hline
\end{tabular}

3. Tabel Transaksi Detail

Nama Tabel : tbl_transaksi_detail

Primary Key : kode_transaksi_detail

Tabel 4.3 Data Transaksi

\begin{tabular}{|c|c|c|c|}
\hline Field & Type & Panjang & $\begin{array}{c}\text { Keteran } \\
\text { gan }\end{array}$ \\
\hline Kode_transaksi_detail & Int & 50 & $\begin{array}{c}\text { Kode } \\
\text { transaksi } \\
\text { detail }\end{array}$ \\
\hline Kode_transaksi & Begint & 150 & $\begin{array}{c}\text { Kode } \\
\text { transaksi }\end{array}$ \\
\hline Kode_Produk & Varchar & 50 & $\begin{array}{c}\text { Kode } \\
\text { produk }\end{array}$ \\
\hline Nama_Produk & Varchar & 150 & $\begin{array}{c}\text { Nama } \\
\text { produk }\end{array}$ \\
\hline Harga & Varchar & 150 & $\begin{array}{c}\text { Harga } \\
\text { Barang }\end{array}$ \\
\hline Jumlah & Int & 10 & Jumlah \\
\hline
\end{tabular}

4. Tabel Directory

Nama Tabel : tbl_directory

Primary Key : Id_toko

Tabel 4.4 Data Nama Toko

\begin{tabular}{|c|c|c|c|}
\hline Field & Type & Panjang & Keterangan \\
\hline Id_toko & Int & 10 & $\begin{array}{c}\text { Id toko atau } \\
\text { counter }\end{array}$ \\
\hline Nama_toko & Varchar & 50 & Nama Toko \\
\hline Jenis_Usaha & Varchar & 100 & Jenis Usaha \\
\hline Lantai & Varchar & 100 & Lantai Toko \\
\hline
\end{tabular}

5. Tabel Kategori

Nama Tabel : Tabel_kategori

Primary Key : Id_Kategori

Tabel 4.5 Data Kategori

\begin{tabular}{|c|c|c|c|}
\hline Field & Type & Panjang & Keterangan \\
\hline Id_kategori & Int & 10 & $\begin{array}{c}\text { Kategori } \\
\text { produk }\end{array}$ \\
\hline Nama_kategori & Varchar & 100 & $\begin{array}{c}\text { Nama } \\
\text { kategori } \\
\text { produk }\end{array}$ \\
\hline Kode_level & Int & 2 & $\begin{array}{c}\text { Kode level } \\
\text { produk }\end{array}$ \\
\hline Kode_Parent & Int & 5 & $\begin{array}{c}\text { Kode parent } \\
\text { produk }\end{array}$ \\
\hline
\end{tabular}

6. Tabel Produk

Nama Tabel : tbl_Produk

Primary Key : Kode_Produk

Tabel 4.6 Data Produk

\begin{tabular}{|c|c|c|c|}
\hline Field & Type & Panjang & Keterangan \\
\hline Kode_Produk & Int & 10 & $\begin{array}{c}\text { Kode } \\
\text { produk }\end{array}$ \\
\hline Id_Kategori & Varchar & 50 & $\begin{array}{c}\text { Id Kategori } \\
\text { Produk }\end{array}$ \\
\hline Nama_Produk & Varchar & 100 & $\begin{array}{c}\text { Nama } \\
\text { Produk }\end{array}$ \\
\hline Harga & Int & 10 & $\begin{array}{c}\text { Harga } \\
\text { Produk }\end{array}$ \\
\hline Stok & Int & 5 & Stok produk \\
\hline Dibeli & Int & 5 & $\begin{array}{c}\text { Banyaknya } \\
\text { pembelian }\end{array}$ \\
\hline Gbr_Besar & Varchar & 100 & $\begin{array}{c}\text { Gambar } \\
\text { produk kecil }\end{array}$ \\
\hline Deskripsi & Text & & $\begin{array}{c}\text { Gambar } \\
\text { produk } \\
\text { besar }\end{array}$ \\
\hline Tipe_Produk & Varchar & 10 & $\begin{array}{c}\text { Deskripsi } \\
\text { produk }\end{array}$ \\
\hline
\end{tabular}




\section{IMPLEMENTASI}

1. Tampilan Menu website Mall Mesra Indah

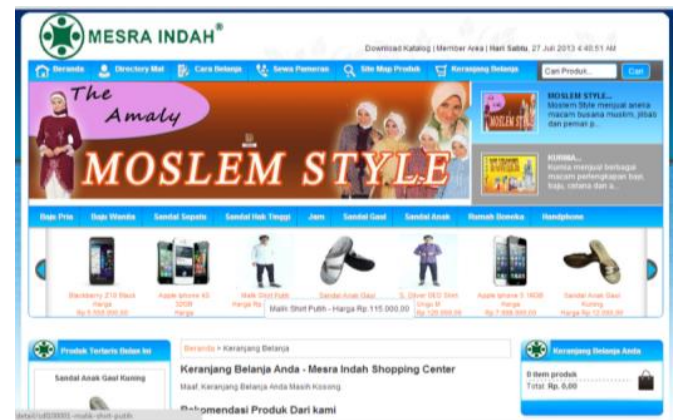

\section{Gambar 3 Tampilan Halaman Website}

Pada gambar 3 diatas adalah tampilan Halaman Website Mall Mesra Indah Samarinda yang terdiri dari menu Beranda, Directory Mall, Sewa Pameran, Cara Belanja, Site Map dan Keranjang Belanja.

2. Tampilan Halaman Login Administrator

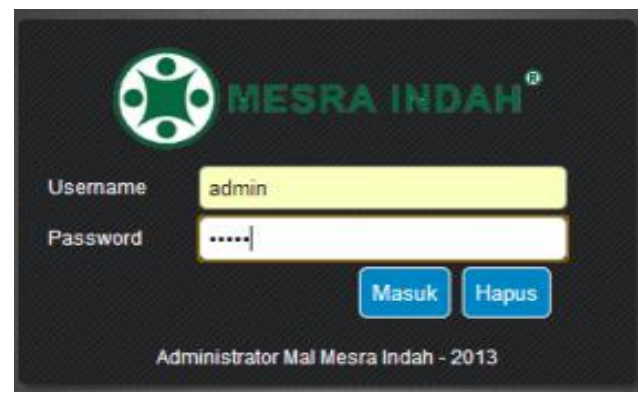

\section{Gambar 4 Tampilan Halaman Login Administrator}

Pada gambar 4 diatas adalah tampilan Halaman login administrator Website Mall Mesra Indah Samarinda yang terdiri dari username dan password.

3. Tampilan Halaman Administrator

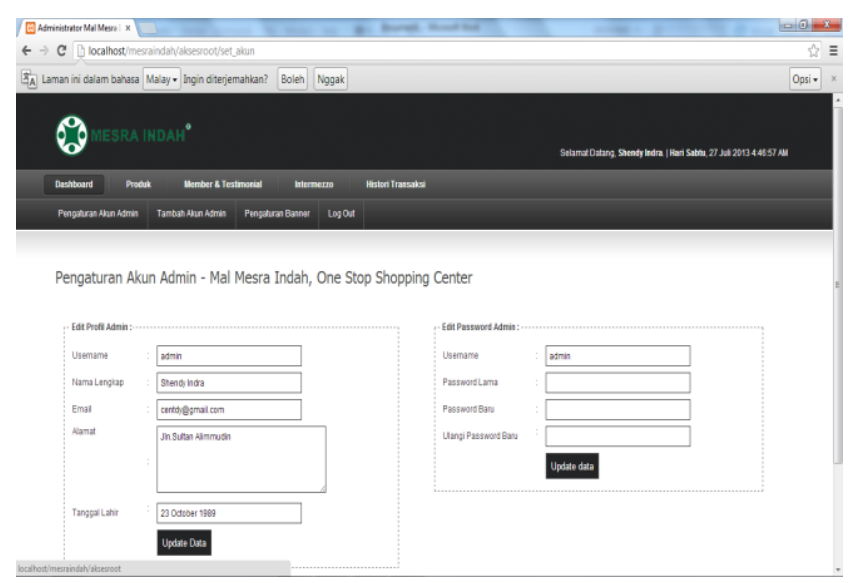

Gambar 5 Tampilan Halaman Administrator
Pada gambar 5 diatas adalah tampilan Halaman dashboard administrator Website Mall Mesra Indah Samarinda terdapat banyak pengaturan didalam halaman website ini antara lain pengaturan akun, pengaturan banner, pengaturan member dan testimonial, produk, pengaturan intermezzo serta menampilkan history transaksi belanja baik dalam hitungan harian, bulanan dan tahunan.

\section{Tampilan Halaman Administrator}

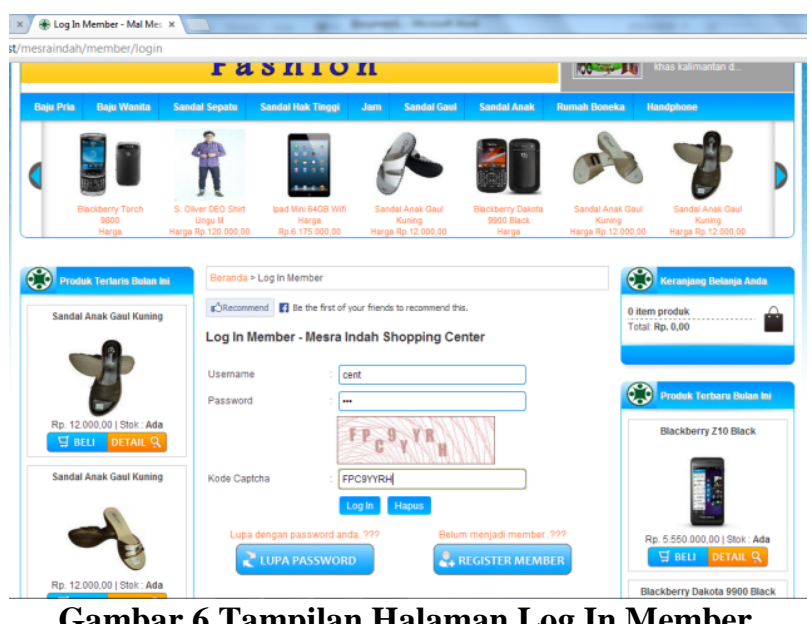

Gambar 6 Tampilan Halaman Log In Member

Pada gambar 6 diatas adalah tampilan Halaman log in member Website Mall Mesra Indah Samarinda terdapat banyak menu username, password, lupa password, dan register member.

5. Tampilan Halaman Administrator

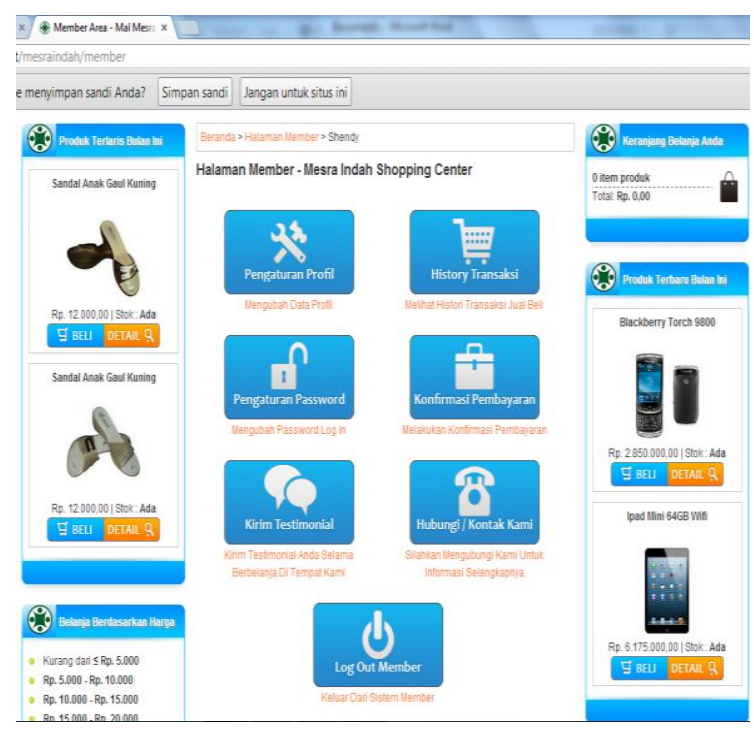

\section{Gambar 7 Tampilan Halaman Member}

Pada gambar 7 diatas adalah tampilan Halaman member Website Mall Mesra Indah Samarinda terdapat banyak menu pengaturan profil, pengaturan password, history transaksi, konfirmasi pembayaran, kirim testimonial, hubungi / kontak kami dan log out member. 


\section{KESIMPULAN}

Kesimpulan dari penelitian. Adalah sebagai berikut :

1. Website ini bisa menampilkan informasi nama toko atau counter yang ada di Mal Mesra Indah.

2. Website ini memberikan informasi produk- produk yang dijual di Mal Mesra Indah.

3. Website ini bisa melayani transaksi pembelian produk secara online dengan pembayaran via Bank khusus yang suah terdaftar menjadi member.

4. Website ini menyediakan fasilitas chat langsung dengan CS via YM dan kirim komentar di testimonial.

5. Website ini menyediakan fasilitas Download Katalog untuk mengetahui apa saja barang-barang terbaru yang dijual di Mal Mesra Indah.

6. Website ini bisa melihat jumlah history transaksi pembelanjaan dalam periode harian, bulanan, dan tahunan.

\section{SARAN}

Saran dari penelitian, apabila suatu saat ada pihak yang terinspirasi untuk melakukan penelitian lebih lanjut dalam rangka mengoptimalkan dan menyempurnakan hasil perancangan website ini.

\section{DAFTAR PUSTAKA}

Sutarman, (2009).Pengantar Teknologi Informasi, Yogyakarta : Bumi Aksara.

Wahana komputer, 2010. Panduan Belajar MySQL Database Server, Jakarta:Media Kita.

Burhan R.M. 2003. Kamus Dunia Komputer dan Internet.Surabaya.Anggota AKAPI

Betha Sidik Ir. 2003. Pemrograman Web dengan HTML

Taha, Deya Arzuningsih.2012. Penerapan Metode user Centered Design (UCD) Untuk meningkatkan Usability Sistem Pemasaran Online. Skripsi. Universitas Negeri Gorontalo.

Jurnal Jessianti dan Sutini, STMIK MDP Palembang (2007).Metode UCD untuk Rancangan Kios Informasi Rumah Sakit Bersalin $\mathrm{XYZ}$ ). 